\title{
As possibilidades investigativas da aprendizagem histórica de jovens estudantes a partir das histórias em quadrinhos
}

\section{The investigative possibilities of historical learning of young students from the comic books}

\author{
Marcelo Fronza ${ }^{1}$
}

\begin{abstract}
RESUMO
O objetivo deste estudo é investigar como a verdade histórica e a intersubjetividade organizam a forma como os jovens tomam o conhecimento para si. A investigação é estruturada nas relações entre a cultura jovem, as histórias em quadrinhos e a cultura histórica de uma sociedade. (RÜSEN, 2009). Analisam-se possibilidades investigativas existentes na relação entre as histórias em quadrinhos e a aprendizagem histórica de jovens estudantes. Abordam-se os tipos de investigações sobre como as narrativas históricas gráficas entraram na cultura escolar: 1) os quadrinhos ligados ao mercado das histórias em quadrinhos ficcionais com temas históricos; 2) os livros didáticos; 3) as histórias em quadrinhos didáticas na forma de paradidáticos; 4) as histórias em quadrinhos produzidas pelos próprios estudantes; e 5) as narrativas gráficas autobiográficas.

Palavras-chave: cultura histórica; aprendizagem histórica; histórias em quadrinhos.
\end{abstract}

\footnotetext{
ABSTRACT

The aim of this study is to investigate how the historical truth and intersubjectivity organize the way young people take knowledge to themselves.

DOI: $10.1590 / 0104-4060.46051$

1 Universidade Federal de Mato Grosso. Cuiabá, Mato Grosso, Brasil. Campus Cuiabá. Av. Fernando Corrêa da Costa, n 2367. Bairro Boa Esperança. CEP: 78060-900.E-mail: fronzam34@
} yahoo.com.br 
This research is structured in relations between the youth culture, comic books and the historical culture of a society. (RÜSEN, 2009). Investigative possibilities were analyzed in the relationship between comic books and historical learning of young students. The types of investigations on the graphic historical narratives into the school culture are discussed: 1) the comic books linked to the market for fictional histories in historical comic books; 2) textbooks; 3) the histories in didactic comic books in the form of textbooks; 4) the comic books produced by the students themselves; and 5) the autobiographical graphic narratives.

Keywords: historical culture; historical learning; historical comic books.

\section{Introdução}

Este artigo tem como objetivo investigar como a verdade histórica e a intersubjetividade estão relacionadas com a forma como os jovens tomam o conhecimento para si a partir destes conceitos. Procuro compreender como as ideias históricas de segunda ordem - tais como a intersubjetividade e a verdade histórica -, produzidas pelos jovens estudantes do Ensino Médio, mobilizam conceitos substantivos por meio da aprendizagem histórica com histórias em quadrinhos ${ }^{2}$.

Este trabalho é produzido a partir do grupo de professores historiadores ligado ao Laboratório de Pesquisa em Educação Histórica da Universidade Federal do Paraná (LAPEDUH/UFPR) e faz parte do projeto de pesquisa "Os jovens e as ideias de verdade histórica e intersubjetividade na relação com as narrativas históricas visuais", vinculado ao grupo de pesquisa "Grupo Pesquisador Educação Histórica: Didática da História, consciência histórica e narrativas visuais", da Universidade Federal de Mato Grosso (GPEDUH/UFMT). Insere-se no conjunto de pesquisas relativas à linha de investigação ligada à cognição histórica situada (SCHMIDT, 2009, p. 22), que tem como princípios e finalidades a própria ciência da História e servem de embasamento à área de pesquisa da Educação Histórica, um campo de investigação que estuda as ideias históricas dos sujeitos em con-

2 O historiador inglês Peter Lee (2005) estabelece alguns princípios da cognição histórica: os conceitos substantivos referem-se aos conteúdos específicos da História, tais como Egito Antigo, Império Romano, Renascimento, Revolução Industrial, etc.; e os conceitos de segunda ordem, que estão ligados às ideias históricas estruturais do pensamento histórico, qualquer que seja o conteúdo, tais como as categorias temporais como mudança histórica e também aquelas relacionadas às formas de compreensão histórica, como os conceitos de explicação histórica, evidência, inferência, significância, imaginação, objetividade, verdade e narrativa históricas. 
textos de escolarização, de tal forma que é estruturada por pesquisas empíricas que dialogam com a teoria da consciência histórica. (RÜSEN, 2001, 2012).

Entendo que a escola é o espaço da experiência social, onde a cultura se manifesta, incluindo aí a cultura juvenil e seus respectivos artefatos da cultura histórica, como as histórias em quadrinhos, que participam de uma estrutura de sentimentos contemporânea. (WILLIAMS, 2003; DUBET; MARTUCCELLI, 1998; HOBSBAWM, 1995; SNYDERS, 1988, RÜSEN, 2007, 2009).

Pretendo, com isso, investigar as diferentes possibilidades investigativas que existem na relação entre as histórias em quadrinhos e a aprendizagem histórica de jovens estudantes do Ensino Médio. Em minhas pesquisas encontrei quatro tipos de investigações relativas à forma como as narrativas históricas gráficas entraram na cultura escolar: 1) por meio dos quadrinhos ligados ao mercado das histórias em quadrinhos ficcionais com temas históricos, que professores e estudantes traziam para o espaço escolar; 2) através dos livros didáticos; 3) por meio de histórias em quadrinhos didáticas na forma de paradidáticos; e 4) as histórias em quadrinhos produzidas pelos próprios estudantes.

\section{As narrativas gráficas como mobilizadoras das experiências dos jovens com o conhecimento histórico na cultura escolar}

As histórias em quadrinhos são compreendidas como artefatos narrativos da cultura juvenil que permitem aos jovens desenvolver uma relação de intersubjetividade com o conhecimento histórico. Por isso, é vital investigar o que, para os jovens, é plausível nas narrativas históricas gráficas e qual é a especificidade que a relação de intersubjetividade com a História fornece no processo de formação de sua identidade. Entendo que a cultura juvenil, no âmbito da cultura escolar, manifesta, nos estudantes, uma determinada forma de operar historicamente com os quadrinhos.

A cultura histórica, que é a expressão da memória histórica de uma comunidade (RÜSEN, 2009, p. 1) e está baseada no princípio da narrativa, pode ordenar temporalmente os procedimentos da cultura escolar, a partir da experiência que os jovens têm com o conhecimento. Para isso, compreendo como necessário ter como critério de verdade básico uma intersubjetividade pautada em narrativas históricas com valores ligados à humanidade enquanto igualdade. Com isso, a cultura histórica estrutura as expressões de uma unidade de consciência em relação às estratégias científicas, às formas da criação artística, à educação, à luta 
pelo poder, tudo isso ligado aos procedimentos da memória histórica pública. (RÜSEN, 2009, p. 1-3).

É por causa da função narrativa, estruturada por um fio condutor de sentido, que as histórias em quadrinhos e outras narrativas históricas visuais podem contribuir para esse processo de libertação dos sujeitos. A função narrativa das histórias em quadrinhos diz respeito às formas de expressão da cultura jovem. A "unidade global da memória histórica", expressa no narrar dos sujeitos, sintetiza e integra as funções da legitimação, da crítica, do ensino, do entretenimento, das imagens e dos mais variados modos de rememorar o passado. A rememoração histórica se dá por meio de uma operação mental do "ato de contar histórias". A plausibilidade narrativa ligada à consciência histórica transforma o procedimento mental da rememoração histórica em formas de narrar a História. (RÜSEN, 2009, p. 8-9).

Partindo da teoria da consciência histórica de Jörn Rüsen, podemos afirmar que as histórias em quadrinhos mobilizam dois tipos de ideias: os nomes próprios e as imagens semióforas. Os nomes próprios ${ }^{3}$ são conceitos substantivos voltados para a estruturação de ideias e histórias que fornecem um fio narrativo para a construção de interpretações históricas. (RÜSEN, 2007, p. 93; SOBANSKI et al., 2010, p. 24). Já como "portadoras de sentido" ou "semióforas", as imagens fascinam a consciência histórica. Elas têm uma função importante na produção de interpretações históricas da experiência do tempo e um papel relevante na construção de modelos interpretativos: podem ser "princípios transmissores de significados e geradores de sentido na interpretação temporal". (RÜSEN, 2009, p. 9-10). As imagens e símbolos, dentre os quais podem ser aproximados, por analogia, os nomes próprios, interferem na atividade rememorativa da consciência histórica, mas não são histórias. Contudo, geram as histórias. A função narrativa das imagens e dos nomes próprios se objetiva quanto se tornam marcos para a formação de uma interpretação histórica. Com isso, as imagens ocupam o lugar de uma história. Em outras palavras, são uma "abreviação narrativa" que fornece sentidos e significados para algum tipo de narração histórica ou elementos para a construção de uma história. (RÜSEN, 2009, p. 9-10).

Para David Carrier (2000, p. 73), seguindo as ideias de Arthur C. Danto (2007, p. 342, 343), a narrativa sequencial dos quadrinhos segue a estrutura da consciência histórica. A consciência do presente é entendida como um dos momentos de uma sequência temporal contínua (não necessariamente linear) e se refere à compreensão de que o futuro é um elemento do passado do sujeito e a narrativa histórica é estruturadora do presente no fluxo entre seu futuro e o seu passado.

3 Os nomes próprios - tais como Júlio César, D. Pedro I, América portuguesa, Copa do mundo, Declaração dos Direitos dos Homens e do Cidadão de 1789, Governo Geisel - são conceitos geralmente baseados nas fontes históricas de uma determinada época, mas podem, também, receber seus nomes posteriormente pelos historiadores. Essas ideias referem-se aos estados de coisas e sujeitos do passado em sua ocorrência singular em um contexto histórico. 
Danto (2007) afirma que a explicação histórica se constitui pela conexão argumentativa e narrativa de diferentes momentos. Narra como o mundo se transforma no tempo. Carrier (2000, p. 14), seguindo essa ideia, aponta que as narrativas históricas gráficas também conectam dois momentos distintos representados por cada quadro. No entanto, sua argumentação é constituída na articulação estética entre enunciados escritos e imagens simbólicas ou realistas, que produzem a possibilidade do narrar.

A partir dessa concepção, podemos constatar que: 1) por meio da teoria dos quadrinhos, as histórias em quadrinhos que abordam temas históricos são em si narrativas históricas gráficas, portanto, narrativas históricas esteticamente estruturadas (CARRIER, 2000; EISNER, 1999, 2005; McCLOUD, 2005, 2006; FRONZA, 2007, 2012); e que, 2) segundo os historiadores ligados ao campo de investigação da Educação Histórica, a narrativa histórica é o construto próprio da expressão do pensamento histórico e da aprendizagem da formação histórica. (RÜSEN, 2001, 2007, 2012). Ou seja, a narrativa se estrutura na concepção básica de que alguém conta a alguém uma história sobre uma experiência do passado interpretada no presente e que cria expectativas de futuro, tal como expressa a história em quadrinhos sul-africana Vusi goes back. A comic book about the history of South Africa. (RÜSEN, 2001, p. 158).

\section{FIGURA 1 - HISTÓRIA EM QUADRINHOS COMO IMAGEM SEMIÓFORA}

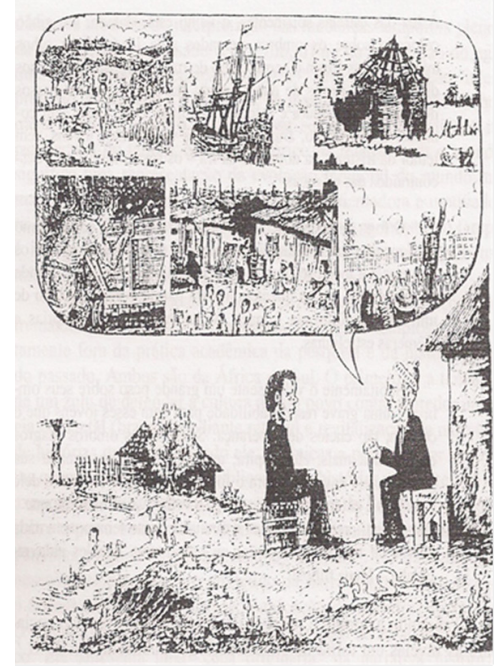

FONTE: Vusi goes back. A comic book about the history of South Africa. (Prezanian Comix, E.D.A.); de um manual para "trabalhadores comunitários", 1981, fig. p. 2. (RÜSEN, 2001, p. 158). 
A partir desta narrativa gráfica compreendo que as imagens não falam por si mesmas, pois são naturezas-mortas mobilizadas pelas ideias históricas dos sujeitos. Esta história em quadrinhos narra uma versão da história sul-africana, desde sua origem até os movimentos de resistência antiapartheid, e busca construir um ordenamento temporal do conteúdo a partir da estrutura básica da narrativa: alguém conta a outra pessoa como eles se tornaram o que são no presente, com vistas a novas perspectivas de futuro. Creio que é importante ler qualquer história em quadrinhos a partir dos diálogos dos seus personagens, pois ali são expressas as ideias que problematizam as carências da vida prática. Portanto, é a estrutura narrativa que define as histórias em quadrinhos. Então, como se constituem as investigações sobre esses artefatos da cultura histórica em sua relação com a cultura escolar?

\section{Para uma tipologia das investigações sobre as narrativas históricas gráficas no interior da cultura escolar}

A estrutura narrativa é o que define as histórias em quadrinhos e, por isso, é relevante para este estudo tecer considerações sobre como as investigações sobre esses artefatos da cultura histórica se apresentam na cultura escolar.

Tendo como objetivo verificar como as histórias em quadrinhos, enquanto artefatos da cultura histórica, entraram na cultura escolar, constatei (FRONZA, 2007) que não foi por meio dos currículos oficiais. Talvez isso tenha ocorrido devido à percepção pública negativa que muitos agentes sociais, tais como educadores, padres, políticos e parte da imprensa, tinham desses artefatos da cultura histórica durante grande parte do século XX. (GONÇALO JUNIOR, 2004, p. 273-284). Mas constatou-se que os quadrinhos foram incorporados à cultura escolar de outras formas que já estão sendo pesquisadas.

As investigações sobre como as narrativas históricas gráficas entraram nas escolas se apresentam tipologicamente em quatro formas que se entrecruzam: 1) por meio dos quadrinhos ligados ao mercado das histórias em quadrinhos ficcionais com temas históricos, que professores e estudantes traziam para o espaço escolar; 2) através dos livros didáticos; 3) a partir de histórias em quadrinhos didáticas na forma de paradidáticos; e 4) através das histórias em quadrinhos produzidas pelos próprios estudantes. Algumas investigações trazem um quinto tipo: 5) a introdução, nas escolas, de quadrinhos biográficos, autobiográficos ou investigativos sobre pessoas que viveram alguns dos grandes eventos históricos da modernidade, tais como a Guerra Civil Americana, a Primeira Guerra Mundial, o holocausto nazista, as bombas de Hiroshima, as revoltas populares 
nos países do Terceiro Mundo, a guerra de libertação da Palestina, a formação do movimento estudantil de um país, a constituição do modo de viver ocidental, etc. (WITEK, 1989; GUNDERMANN, 2007).

a) Histórias em quadrinhos ficcionais com temas históricos no interior da cultura escolar

As pesquisas referentes ao primeiro tipo têm dois vieses de investigação: o primeiro é a abordagem sobre como se desenvolveram as condições históricas para que as histórias em quadrinhos entrassem na cultura escolar. (BONIFÁCIO, 2005; BARBOSA, 2006). Para Selma Bonifácio (2005, p. 119-166), quadrinhos históricos ficcionais, tais como a coleção Você sabia? da Turma da Mônica, de Maurício de Souza, permitem processos de didatização históricos específicos para sua linguagem, que implicam ressignificações e um diálogo com as fontes e a historiografia mediados por outras narrativas visuais, como pinturas e filmes históricos. No entanto, na maior parte dos quadrinhos ficcionais que entram na cultura escolar detecta-se a presença da narrativa tradicional da história nacional, sobretudo aqueles estruturados em torno do calendário cívico escolar.

FIGURA2 - HISTÓRIAS EM QUADRINHOS NA CULTURA ESCOLAR: TURMA DA MÔNICA

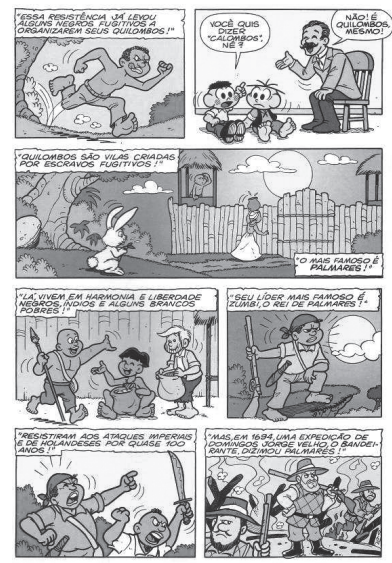

FONTE: SOUZA (cerca de 2005, p. 29).

4 Estudarei essa quinta forma de aparição dos quadrinhos na cultura escolar de modo mais aprofundado em trabalhos futuros, pois ela, além de apresentar análises mais recentes produzidas sobre o tema na Alemanha, França, Estados Unidos e América Latina, está intimamente relacionada às narrativas que tematizam a intersubjetividade a partir da orientação de sentido para a vida prática, tais como no caso de Mauss, Chibata, entre outros. 
Um exemplo disso é análise do exemplar relativo à Abolição dos escravos (BONIFÁCIO, 2005, p. 119-166), onde a autora apresenta uma descrição do processo de abolição da escravatura partindo da história da escravidão negra e indígena, o tráfico negreiro, a história do quilombo dos Palmares e a Lei Áurea. Esta história em quadrinhos segue o padrão da história tradicional curricularizada, ou seja, apesar de introduzir o humor e a imaginação nas aulas de História, esses artefatos afirmam a tradição dominante na cultura histórica presente na escola. No entanto, a investigação desse tipo de histórias em quadrinhos ficcionais fornece alternativas válidas para as pesquisas sobre como determinados conceitos substantivos da História estão presentes na consciência histórica dos jovens. Também permite problematizar a força das concepções tradicionais da História no uso público desse conhecimento no interior da cultura escolar.

O segundo viés investigativo do tipo de pesquisa se refere às investigações que abordam como os jovens mobilizam ideias históricas, a partir de narrativas históricas gráficas ficcionais. (FRONZA, 2007). Nesta investigação constatei que os jovens mobilizam ideias históricas substantivas ligadas aos conteúdos históricos escolares e às suas experiências culturais (contos de fada, experiências escolares, relação com filmes e internet) e estruturadas por meio de conceitos de segunda ordem como a significância e a inferência históricas. No entanto, essa mobilização conceitual foi realizada por uma operação do narrar ficcional.

Procurei, por meio de uma investigação qualitativa, enfrentar as questões sobre qual é a relação entre as histórias em quadrinhos e os sujeitos em escolarização e quais são os significados que os jovens dão às histórias em quadrinhos.

Para compreender quais os significados que os jovens dão ao conhecimento histórico, presentes nas histórias em quadrinhos, utilizei um instrumento de investigação empírico, que permitiu a produção de inferências em relação a uma história em quadrinhos com temas históricos. (FRONZA, 2007, p. 67-146, 160-169). Aplicado em 35 jovens de uma escola pública de Curitiba, Paraná, no dia 31 de julho de 2006, este instrumento de investigação era constituído, inicialmente, por um quadro de questões referentes aos dados socioculturais desses sujeitos e por um questionário que continha 18 questões, sendo que 1 antecedidas pelo quadro de dados citado - eram de caráter geral sobre a investigação (primeira parte do instrumento de investigação) e 7 eram específicas em relação à história em quadrinhos apresentada (segunda parte do instrumento de investigação). Entre estas questões estavam intercaladas às três páginas finais da história em quadrinhos Asterix e Cleópatra (GOSCINNY; UDERZO, 1985, p. 46-48), acompanhadas de questões abertas e fechadas, relativas a quais significâncias históricas os sujeitos davam aos personagens e situações do passado expressas neste artefato cultural. 
FIGURA 3 - HISTÓRIAS EM QUADRINHOS NA CULTURA ESCOLAR: ASTERIX

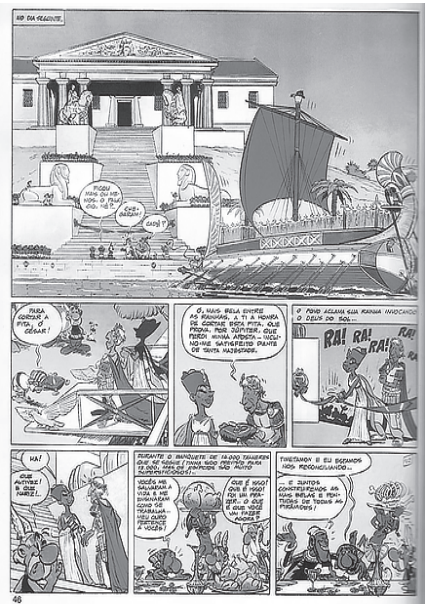

FONTE: GOSCINNY; UDERZO (1985, p. 46).

Do resultado da análise dessa relação entre esses sujeitos e as narrativas gráficas pude chegar a alguns pressupostos metodológicos.

O primeiro pressuposto, que o professor historiador precisa ter claro, é que sua intervenção pedagógica na aula de História necessita respeitar a estrutura narrativa e conceitos próprios à natureza desses artefatos culturais. Valorizar a empatia que os quadrinhos causam nos jovens em relação ao conhecimento histórico é fundamental. Segundo os estudantes investigados, o uso das histórias em quadrinhos, por si só, já permite uma aprendizagem histórica significativa, pois eles gostam e leem esses artefatos culturais.

A construção dos dados e o confronto com o referencial teórico me possibilitaram inferir que os jovens investigados gostam e leem histórias em quadrinhos e fazem uso desses artefatos culturais, tanto na sala de aula, como em outros espaços de experiências culturais. (SNYDERS, 1988). Eles relacionam os quadrinhos com uma aprendizagem divertida e com a facilidade de leitura, permitindo uma melhor memorização dos conteúdos.

Estratégias que se utilizem do humor e da estrutura narrativa das histórias em quadrinhos permitem, conforme os sujeitos da investigação afirmaram, uma melhor memorização do conteúdo e, principalmente, a elaboração de um significado histórico ou sentido, relacionados ao conhecimento histórico. Segundo alguns deles, as histórias em quadrinhos permitem a constituição de um sentido de identidade, ligado a uma cultura juvenil de sua época. (HOBSBAWM, 1995, p. 326). Esses sujeitos históricos percebem os potenciais dos 
quadrinhos, principalmente em relação aos mangás japoneses e às histórias de Hagar e Asterix, que utilizam personagens de cartum com cenários históricos realistas, na possibilidade de uma passagem de ideias históricas prévias, baseadas na cultura primeira, para ideias históricas elaboradas e sustentadas por uma cognição histórica situada. Esses aspectos vão ao encontro de uma abordagem que considera as histórias em quadrinhos como inferências e evidências constituidoras de narrativas históricas.

Nas discussões teóricas relativas à significância histórica (SEIXAS, 1994) e à narrativa histórica (RÜSEN, 2001), encontrei fundamentos para entender as respostas que os jovens me forneceram a partir daquele instrumento de investigação. Compreendi a significância histórica de uma experiência do passado a partir de alguns critérios utilizados pelos historiadores: a) os historiadores analisam se a experiência do passado "afetou um grande número de pessoas por um longo período de tempo"; b) se estabelecem a sua relação com outra(s) experiências(s) histórica(s); c) se estabelecem a sua relação com as experiências culturais do presente, "e também com suas próprias vidas". (SEIXAS, 1994).

Portanto, as ideias de significância e inferência históricas, advindas da epistemologia da História, permitem a estruturação de uma aprendizagem histórica situada que considere a complexidade narrativa do pensamento histórico. A partir desses critérios, busquei compreender como os jovens estudantes tornam significativa uma experiência histórica, quais são as ideias históricas que estruturam a significância dessas experiências do passado e que relações esses sujeitos históricos estabelecem com suas vidas e com sua comunidade.

Constatei que os jovens construíram explicações não históricas quando entraram em contato com quadrinhos que não trabalhavam, em última instância, com elementos didáticos do conhecimento histórico. Isto porque a questão relativa à ficção e verdade, ao pensamento ficcional e ao pensamento plausível, possibilita que eu insira a ideia de intersubjetividade como uma escolha teórica. O poder da dimensão estética da cultura histórica sobre o modo de narrar dos jovens estudantes, articulado às premissas relacionadas à plausibilidade das narrativas históricas, dentro teoria da consciência histórica, me levaram à categoria da intersubjetividade como um dos elementos constituidores do pensamento histórico.

b) Histórias em quadrinhos históricas ou ficcionais nos livros didáticos de História

Este tipo de pesquisa também apresenta dois vieses interpretativos distintos. O primeiro deles diz respeito à análise histórica sobre o livro didático em forma de histórias em quadrinhos de Julierme, muito utilizado, nas escolas 
públicas, durante as décadas de 1970 e 1980. (BONIFÁCIO, 2005; NERES, 2005). Segundo Selma Bonifácio (2005, p. 92), os livros didáticos de Julierme apresentavam uma concepção de ensino de História na qual os quadrinhos se aproximavam do "conhecimento e [d]a retenção de informações pontuais, vinculadas a uma narrativa genérica de um conteúdo que se oferecia como 'toda a História' ou 'o essencial da História'". Essa concepção de um ensino objetivo estava relacionada a uma compreensão da História como conhecimento objetivo tradicional.

FIGURA 4 - HISTÓRIAS EM QUADRINHOS NOS LIVROS DIDÁTICOS DE HISTÓRIA: JULIERME

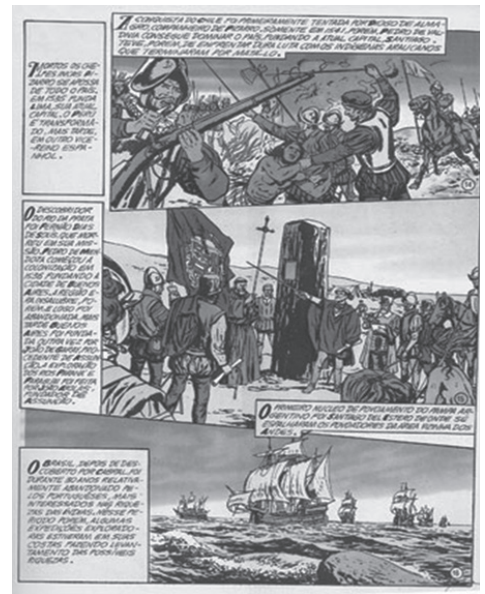

FONTE: CASTRO; ZALLA (1971).

O estilo didático dos quadrinhos de Julierme, como o apresentado na passagem relativa à conquista da América pelos europeus, presente no livro História Geral - História para a Escola Moderna (CASTRO; ZALLA, 1971), seguindo a interpretação de Bonifácio (2005, p. 94), apresenta o aspecto mais fragilizado da obra didática, pois ao apresentar um dinamismo e uma ação, cada enquadramento está fechado e isolado em relação aos demais. Essa sensação se acentua pelo predomínio de textos nas legendas. Essa disposição dos textos acaba por deviar a atenção do leitor em relação à narrativa histórica tematizada, já que a imobilidade da imagem somada ao excesso de informação torna a experiência de leitura textual mais cansativa. Outra limatação estética na didática dos quadrinhos de Julierme pode ser a ausência de outros recursos, como balões e onomatopeias. É perceptível, nesta investigação, como os elementos estéticos 
de uma narrativa histórica gráfica podem, por meio da imagem, potencializar as possibilidades de desenvolvimento do aprendizado histórico, mas, ao mesmo tempo, a limitação das características estéticas relativas ao texto podem se contrapor e atenuar o poder imaginativo das imagens. No entanto, mesmo com essas características os quadrinhos de Julierme marcaram uma geração inteira de estudantes brasileiros.

O segundo viés investigativo é o que, segundo os critérios da pesquisa qualitativa articulado com a perspectiva da Educação Histórica, busca entender como as histórias em quadrinhos aparecem em coleções de manuais didáticos de História aprovados pelo Programa Nacional do Livro Didático (PNLD). No caso, foram investigados os manuais de história aprovados no PNLD de 2002, relativo ao Ensino Fundamental. (FRONZA, 2007).

Primeiramente, investiguei como as histórias em quadrinhos eram trabalhadas em coleções de livros didáticos de História, seguindo uma hipótese inicial de que estes artefatos culturais podem ser apresentados nos manuais sob duas formas distintas e talvez contraditórias:

- Como ilustração para determinado conteúdo. Essa forma ilustrativa da utilização das histórias em quadrinhos pode se relacionar ou não com algum elemento registrado no texto que aborda o conteúdo;

- Como documentos ou fontes históricas que problematizam os conteúdos sendo, assim, um instrumento para a produção do conhecimento histórico pelos sujeitos escolares.

A esse respeito, a historiadora inglesa Rosalyn Ashby (2006, p. 160, 167-168) aponta que, na investigação histórica, os documentos devem ser compreendidos como vestígios ou fontes onde é possível inferir ou deduzir sobre o passado. Para isso, deve-se distinguir com clareza os conceitos de fonte e evidência, os quais não devem ser confundidos. A evidência é uma relação plausível entre uma interpretação histórica e os documentos. Já os documentos são fontes válidas ou não em relação àquela interpretação histórica. É a evidência que fornece a plausibilidade desta validade.

Com isso, passei à construção de um estudo exploratório que investigou três histórias em quadrinhos presentes nas coleções de livros didáticos de História escolhidas. (SCHMIDT, 2002; CABRINI; CATELLI JUNIOR; MONTELLATO, 2004) $)^{5}$.

5 A escolha dessas duas coleções de manuais didáticos de história não se deu necessariamente porque são de caráter temático, mas sim por outros dois motivos, um de ordem qualitativa e outro de ordem pragmática: 1) estão entre os livros que receberam uma boa classificação no PNLD de $2002 ; 2$ ) foram os primeiros livros com uma boa classificação no PNLD que tive a possibilidade de analisar no momento da construção de um trabalho para o VII Encontro Nacional de Pesquisadores do Ensino de História (VII ENPEH). Para os critérios de análise e a respectiva interpretação das 
FIGURA 5 - HISTÓRIAS EM QUADRINHOS NOS LIVROS DIDÁTICOS DE HISTÓRIA: FONTE HISTÓRICA

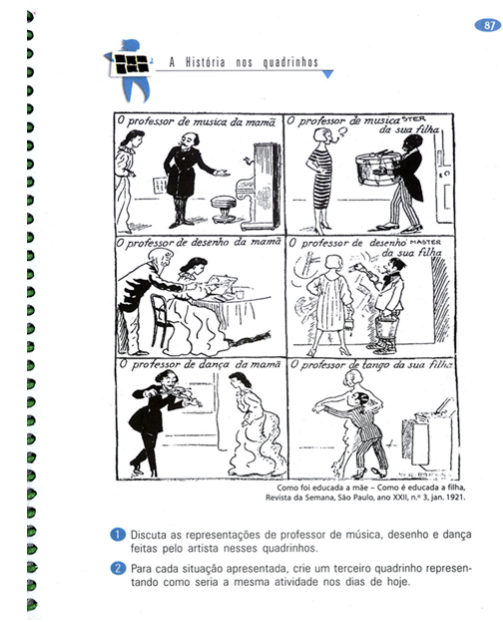

FONTE: COMO FOI EDUCADA A MÃE - COMO É EDUCADA A FILHA. Revista da Semana, São Paulo, ano XXII, n. 3, jan. 1921. (SEVCENKO, $1988^{6}$ apud SCHMIDT, 2002, p. 87).

As estratégias didáticas voltadas à história em quadrinhos Como foi educada minha mãe - como é educada a filha (SCHMIDT, 2002, p. 87), apresentada no livro didático, são as seguintes: primeiramente, há uma seção específica para essa imagem no livro; depois, apresenta atividades relacionadas à história em quadrinhos que pedem para os jovens discutirem as representações referentes aos personagens e a construção de um terceiro quadrinho para cada situação representada na imagem; por fim, a história em quadrinhos está no final da unidade com o objetivo de preparar os alunos para o estudo da unidade seguinte, a qual se refere à educação. No entanto, em nenhum momento as estratégias didáticas utilizam os elementos estruturais dos quadrinhos para o desenvolvimento das atividades. Contudo, essa observação pode ser matizada ao se considerar que a primeira atividade pede uma discussão sobre a representação das imagens

histórias em quadrinhos investigadas ver Fronza (2007, p. 58-66, anexos 1 e 2, p. 156-159). As histórias em quadrinhos em questão são: PAIVA, Miguel. Chiquinha. (SCHMIDT, 2002, p. 103) ( $5^{\mathrm{a}}$ série); COMO FOI EDUCADA A MÃE - COMO É EDUCADA A FILHA. Revista da Semana, São Paulo, ano XXII, n. 3, jan. 1921. (SEVCENKO, 1988, p. 369 apud SCHMIDT, 2002, p. 87) (6 $6^{\mathrm{a}}$ série); e MAIA, Luiz. Sem título (ilustração). (CABRINI; CATELLI JUNIOR; MONTELLATO, 2004, p. 15) (5 série).

6 SEVCENKO, N. História da vida privada no Brasil 3: república: da Belle Époque à era do rádio. São Paulo: Companhia das Letras, 1988. p. 369 (reprodução). 
dos personagens. Isso pode levar à aproximação da ideia de ícone proposta por McCloud (2005, p. 26) como um elemento estrutural dos quadrinhos, pois ele se refere "[...] a qualquer imagem que represente uma pessoa, local, coisa ou idéia".

Já na descrição iconográfica se percebe o valor documental da história em quadrinhos, além da data de sua publicação (1921), pois nela está clara a relação com o conhecimento histórico, principalmente ao representar a articulação entre permanências e mudanças por meio das atitudes das diferentes gerações. O aprofundamento da análise desta relação temporal é reforçado implicitamente pelas atividades. A orientação temporal é uma categoria vital da epistemologia da História que deve ser trabalhada nas histórias em quadrinhos. (RÜSEN, 2001). Contudo, mesmo que os quadrinhos se apresentem em alguns livros didáticos de História sem uma análise aprofundada de sua natureza estética não quer dizer que os jovens não desenvolvam uma aprendizagem elaborada, pois estes sujeitos entendem que alguns dos elementos fundamentais desses artefatos, como o humor e sua estrutura narrativa, por exemplo, facilitam muito a apreensão do conhecimento histórico elaborado. O problema é que esses elementos e estratégias não estão sistematizados nesses manuais.

\section{c) Histórias em quadrinhos didáticas}

Para resolver esse problema fiz uma apropriação do terceiro e quarto tipos de aparição dos quadrinhos históricos na cultura escolar, quais sejam, os livros paradidáticos na forma de histórias em quadrinhos e a produção pelos jovens de narrativas visuais ${ }^{7}$. Esses tipos de investigação estão relacionados com o campo de pesquisa da Educação Histórica, pois buscam investigar as ideias históricas dos alunos em contexto de escolarização.

O confronto dos quadrinhos históricos construídos didaticamente com o objetivo de verificar se os jovens mobilizam as operações mentais ligadas a conceitos de segunda ordem está presente nas investigações sobre evidência ou

7 Em que pese o fato de eu investigar esse tema, não encontrei nenhuma pesquisa com estes dois vieses quando os assuntos são os quadrinhos de história paradidáticos e a produção de quadrinhos históricos por jovens no ensino de História. Sobre quadrinhos paradidáticos existem artigos sobre a relação dos paradidáticos com a literatura, o meio ambiente e o desenvolvimento da leitura, mas não consegui encontrar investigações que façam um mapeamento sobre os quadrinhos paradidáticos em História. Por outro lado, encontrei algumas pesquisas que trabalham com quadrinhos produzidos por jovens e crianças, mas não focados no ensino de História. No entanto, para relativizar essa constatação, conheço um grupo de professoras mineiras, da cidade de Leopoldina-MG, que estão trabalhando intensamente com crianças e jovens de escolas públicas com o fomento da leitura e produção de quadrinhos históricos por esses sujeitos. Inclusive elas divulgam resenhas dos quadrinhos históricos paradidáticos na medida em que vão sendo lançados pelo mercado editorial. Para ter acesso a essa experiência ver $<$ http://www.gibitecacom.blogspot.com/ $>$. 
narrativa histórica, a partir de modelos do Projeto Chata (Concepts of History and Teaching Approaches / Conceitos de Histórias e Abordagens de Ensino). (LEE, 2006; GAGO, 2012).

A evidência histórica é um conceito de segunda ordem fundamental, pois as histórias em quadrinhos devem ser consideradas como fontes históricas que podem fornecer evidências para a sustentação ou refutação das afirmações e interpretações históricas desenvolvidas por historiadores, professores historiadores e estudantes em relação a determinado tema histórico. Mas, para a historiadora inglesa Rosalyn Ashby, é necessário que se faça uma clara diferenciação entre as fontes e as evidências, as quais estão claramente relacionadas ao contexto da aprendizagem histórica:

Geralmente as palavras "evidência" e "fonte" são usadas como recíprocas, e tanto professores como alunos devem fazer claras distinções aqui. É particularmente preocupante quando, na tentativa de ajudar os estudantes, os professores utilizam materiais comercialmente produzidos na sala de aula que reforçam as noções equivocadas que os alunos possam ter. [...]. Se se quer fazer progresso com os alunos, eles precisam entender que as fontes não são a mesma coisa que evidência, e é preciso desenvolver uma compreensão conceitual da relação de evidência entre fontes e afirmações. (ASHBY, 2006, p. 167-168).

Isso significa que os estudantes devem entrar em contato com as fontes e, além disso, superar o uso delas como simples confirmação de informações relativas a uma interpretação histórica. O professor deve fornecer conhecimento para que os jovens possam criar hipóteses em relação a determinado conteúdo histórico. Esse aspecto é muito relevante quando se consideram as histórias em quadrinhos como fontes históricas, pois o caráter ficcional do enredo de suas narrativas tende a carregar de anacronismos as informações históricas presentes nesses artefatos culturais. Daí a necessidade de confrontar narrativas históricas em quadrinhos relacionados à função didática História.

Isso significa que a investigação das ações históricas necessita do uso da evidência para criar conexões entre o contexto no qual as pessoas se encontraram no passado, as crenças que tiveram sobre esse mesmo contexto e os valores e ideias - enfim, as experiências - que tiveram sobre o seu mundo. Segundo os historiadores ingleses Peter Lee e Rosalyn Ashby (2000, p. 200), a internalização de ideias de segunda ordem mais poderosas (como, por exemplo, a evidência histórica) é talvez o melhor caminho para dar sentido ao desenvolvimento do pensamento histórico dos jovens. 
FIGURA 6 - HISTÓRIAS EM QUADRINHOS DIDÁTICAS: PROJETO CHATA

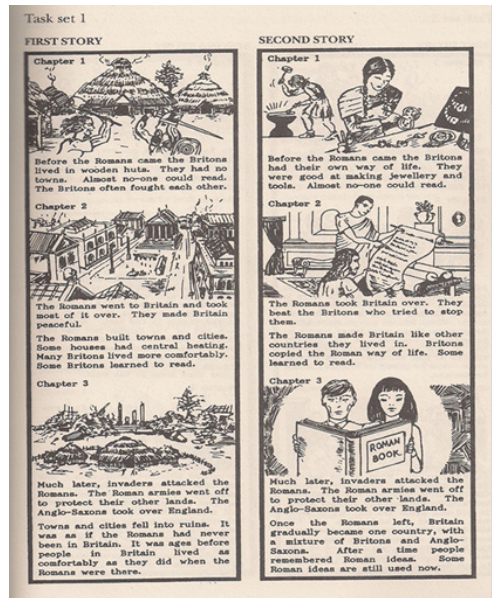

FONTE: LEE (2006, p. 157).

Ao investigar conceitos de segunda ordem como a evidência histórica, o historiador inglês Peter Lee (LEE; ASHBY, 2000; LEE, 2006) traz uma abordagem distinta das histórias em quadrinhos, pois em suas investigações não aborda os conceitos relativos à natureza da linguagem desses artefatos da cultura histórica. Ao contrário, os quadrinhos utilizados foram construídos especialmente para a pesquisa que desenvolveu. Com isso, afirma que os quadrinhos utilizados são relatos fundamentais para que as crianças e os jovens compreendam as ideias históricas, principalmente no que se refere aos conceitos de segunda ordem como a evidência. As histórias em quadrinhos foram pensadas como narrativas históricas em confronto e tinham como finalidade permitir aos estudantes ingleses, a partir de três tarefas, a confrontação das mesmas narrativas. Estas narrativas abordam os seguintes temas: as duas primeiras apresentam aspectos da vida material e de cultura e ideias na relação entre bretões e romanos e buscam investigar as ideias sobre evidência histórica; a segunda tarefa apresenta dois quadrinhos que abordam a questão do fim do Império Romano e procuram saber questões relativas à multiperspectividade das interpretações; a terceira tarefa apresenta narrativas que representam a ocupação saxônica na Grã-Bretanha e procura enfrentar a questão da veracidade destas narrativas, ou seja, se o que relatam aconteceu ou não. (LEE; ASHBY, 2000, p. 204; LEE, 2006, p. 145-146).

É preciso atentar para o fato de que Peter Lee, em relação às histórias em quadrinhos utilizadas em sua pesquisa, não considera como relevantes os elementos estéticos próprios à natureza deste artefato da cultura histórica, os quais poderiam 
intervir diretamente nas ideias históricas das crianças e jovens ingleses e, por consequência, nas categorizações construídas por ele. Inclusive estas narrativas foram construídas com a intenção de remover estes aspectos estéticos e anacrônicos.

Concordo com o historiador, no que diz respeito aos problemas que podem advir dos aspectos ficcionais pertencentes em muitas histórias em quadrinhos, tais como Asterix, por exemplo. Neste sentido, sigo o mesmo caminho que a pesquisa de Lee. A minha hipótese é que a mobilização, pelos jovens, das ideias históricas em construtos da narrativa histórica pode ser realizada pela confrontação das histórias em quadrinhos, entendidas enquanto narrativas históricas que possam mitigar o seu poder ficcional e anacrônico. Levando isso em conta, propus o confronto de quadrinhos históricos didáticos que já existem no mercado na busca de compreender se os jovens mobilizam as operações mentais ligadas à verdade histórica e intersubjetividade. (FRONZA, 2012).

O público-alvo da pesquisa foram 125 estudantes, com idades de 14 a 27 anos, do segundo ano do Ensino Médio de quatro escolas públicas brasileiras: São João dos Patos, Maranhão (43 estudantes); Três Lagoas, Mato Grosso do Sul (26 estudantes); Vitória da Conquista, Bahia (33 estudantes); e Curitiba, Paraná (23 estudantes). Os jovens desses colégios foram investigados em maio e outubro de 2011, respectivamente. Para isso, produzi um instrumento de investigação (FRONZA, 2012, p. 450-454) baseado nos critérios metodológicos da pesquisa qualitativa.

Esse instrumento de investigação contém o confronto de fragmentos de duas histórias em quadrinhos, as quais abordam didaticamente, a partir de critérios historiográficos, a temática da Independência do Brasil ocorrida em 7 de setembro de 1822. A primeira, versão A, denominada A Independência do Brasil, foi produzida totalmente por quadrinistas. (DINIZ; EDER, 2008, p. 41-45).

FIGURA 7 - HISTÓRIAS EM QUADRINHOS DIDÁTICAS: A INDEPENDÊNCIA DO BRASIL

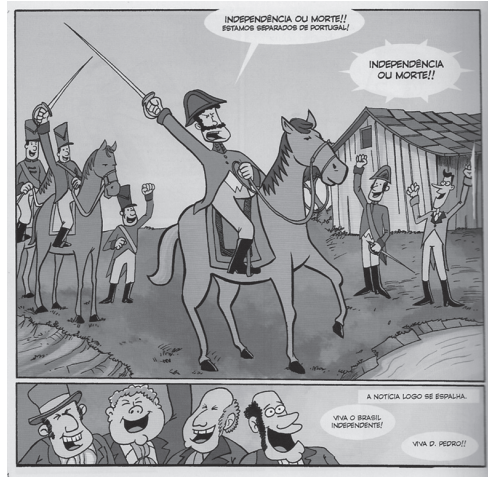

FONTE: DINIZ; EDER (2008, p. 44). 
A segunda história em quadrinhos, a versão B, chamada Da Colônia ao império: um Brasil pra inglês ver..., foi roteirizada pela historiadora brasileira Lilia Moritz Schwarcz. (PAIVA; SCHWARCZ, 1995, p. 5-9).

\section{FIGURA 8 - HISTÓRIAS EM QUADRINHOS DIDÁTICAS: DA COLÔNIA AO IMPÉRIO}

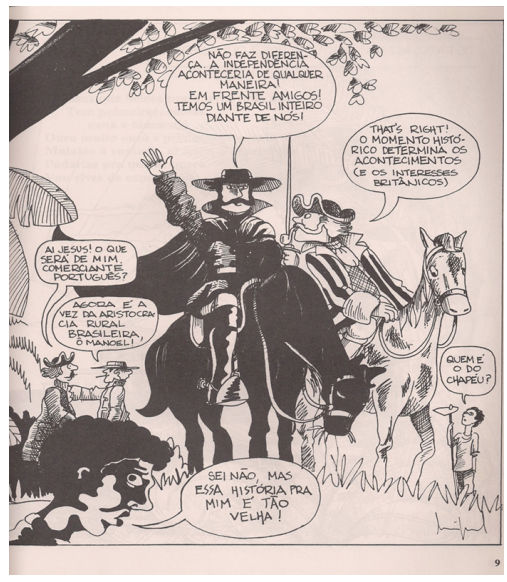

FONTE: PAIVA; SCHWARCZ (1995, p. 9).

Seguindo os critérios de Peter Lee (LEE; ASHBY, 2000; LEE, 2006), essas histórias em quadrinhos procuram evitar anacronismos em relação aos sujeitos e às situações do passado representadas. Mas aqui ocorre o diferencial entre a minha pesquisa e a de Lee. Constatei que o poder dos aspectos anacrônicos e estéticos, próprios à natureza dos quadrinhos, influencia fortemente na compreensão histórica dos jovens estudantes do Ensino Médio. (FRONZA, 2007). No entanto, em investigação posterior (FRONZA, 2012), as histórias em quadrinhos didatizadas historicamente, presentes no instrumento de investigação aplicado aos jovens estudantes do Ensino Médio, também trouxeram elementos narrativos (RÜSEN, 2001), que não são mais determinados pela ficção cômica desses artefatos, mas sim por uma concepção de um passado encapsulado ${ }^{8}$

8 O filósofo da história Michael Oakeshott (2003, p. 60-68) apresenta quatro formas de compreender o passado: 1) o passado encapsulado, que é composto por tudo o que aconteceu aos sujeitos e deixou um resíduo inconsciente, mas que estrutura a sua identidade por meio de experiências do passado ainda não interpretadas; 2) existe o passado lembrado que se relaciona à memória onde o passado e o presente estão vinculados; é a identidade de uma consciência contínua ligada aos valores, compromissos e autoconsciência; 3) há o passado resgatado, também chamado de passado "vivo", que tem relação com o passado lembrado, pois está relacionado à orientação de sentido para os compromissos do presente, mas se distingue no resgate aos fragmentos de infor- 
(OAKESHOTT, 2003, p. 60) e a uma imagem canônica (SALIBA, 1999, p. 434-452), marcados pela ideia de identidade nacional.

Compreendo que os conceitos organizadores das histórias em quadrinhos - narrativa gráfica, empatia, ícone, cartum, conclusão ou preenchimento, timing e mapa temporal (EISNER, 1999, 2005; McCLOUD, 2005, 2006)-influenciam o modo de entendimento histórico dos jovens, mobilizando, agora, conceitos históricos ligados à intersubjetividade e à verdade histórica, por meio do autoconhecimento identitário desses sujeitos. O que eu quero afirmar com isso é que se pode trabalhar com quadrinhos históricos não ficcionais, como fez Peter Lee (LEE; ASHBY, 2000; LEE, 2006), mas não é possível escapar das formas de organização estéticas da cultura histórica em que estes artefatos estão estruturados, quando abordam temas históricos. Em outras palavras, a função estética das histórias em quadrinhos - estruturada pelos conceitos indicados anteriormente - potencializa as ideias sobre o passado, incrustadas na consciência histórica dos jovens estudantes.

Mesmo considerando relevantes essas diferenças, entendo como fundamentais as contribuições das investigações de Peter Lee e Rosalyn Ashby para o desenvolvimento de minha pesquisa, pois constataram que as histórias em quadrinhos podem fazer com que os jovens estudantes atinjam ideias complexas e sofisticadas sobre o passado que está presente em seu pensamento histórico.

Em síntese, é possível a construção da relação entre a verdade histórica e a intersubjetividade mobilizada pelos jovens estudantes do Ensino Médio a partir das histórias em quadrinhos investigadas. Seguindo a perspectiva de Jörn Rüsen (2001), esta relação estrutura-se nas três operações mentais da narrativa histórica: a experiência histórica, a interpretação histórica e a orientação histórica.

Uma atitude de afirmação da tradição predominou entre os jovens que focaram na operação da experiência histórica. Quanto às situações do passado reconhecidas pelos jovens, predominaram às ligadas a situações do passado nacional, tais como o "Grito do Ipiranga", o dia de 7 de setembro, o rio Ipiranga e inclusive uma referência à pintura de Pedro Américo. Também foram muito citadas as situações ligadas ao passado como autoridade da tradição. Todas elas podem ser relacionadas ao conceito de segunda ordem de evidência histórica e a categorias de sujeitos históricos. Essas categorias tenderam a mobilizar uma

mações e às vagas reminiscências, como anedotas, relatos de feitos passados úteis para o presente, ligados a uma memória exemplar; esses passados estão relacionados aos modos como aparecem no presente dando significado e sentido de orientação a ele, mas existe um outro tipo: 4) o passado histórico, que é composto pelos vestígios humanos de um passado desconectado existencialmente com o presente; o passado histórico busca dar significado à singularidade de uma experiência do passado há muito tempo esquecida. 
disposição afirmativa das narrativas tradicionais advindas, principalmente, da cultura escolar.

Quando os estudantes mobilizaram a operação da interpretação histórica apontaram para a existência de perspectivas céticas em relação à veracidade das narrativas históricas em quadrinhos. No entanto, a maioria dos jovens afirmou a possibilidade da verdade e muitos apresentaram modos complexos de explicação causal sobre o passado narrado nas histórias em quadrinhos. A relação com a verdade histórica foi a mais relevante em relação à operação da interpretação histórica, inclusive afirmações contrafactuais foram explicitadas nessas justificativas.

Com relação à operação mental da orientação histórica, a memória histórica como formadora da identidade nacional foi a estratégia mais mobilizada para a demarcação do tipo de intersubjetividade que os jovens têm com as experiências passadas. Um jovem de São João dos Patos apresentou um sentido de orientação no tempo em que as experiências do passado se expressam em sua diferença com as experiências do presente. Citou como exemplo o uso de cavalos no século XIX como uma diferenciação em relação ao presente ligado à utilização de veículos motorizados.

Compreendo que a potencialização de ideias históricas dos estudantes tem a ver com a plausibilidade histórica das narrativas gráficas. Por isso, entendo como necessária a criação de parâmetros que apontem o que é ou não é plausível nessas narrativas históricas em quadrinhos quando está em jogo a orientação de sentido da formação da identidade histórica dos jovens. Com isso, verifiquei se a intersubjetividade está relacionada com a maneira como os jovens tomam para si o conhecimento, se tem a ver com esta fonte que estetiza o passado.

\section{d) Histórias em quadrinhos produzidas pelos jovens estudantes}

Uma quarta possibilidade investigativa são as histórias em quadrinhos produzidas pelos próprios estudantes. A narrativa histórica gráfica é uma das conceitualizações estruturantes das histórias em quadrinhos e isto possibilitou que os jovens desenvolvessem a capacidade de reconstruir suas ideias na forma de uma narrativa. (FRONZA, 2007).

Para entender o poder estético do caráter gráfico dessas narrativas são importantes as considerações de Elias Tomé Saliba relativas às imagens canônicas. Suas ideias sobre as imagens canônicas se aproximam muito das ideias dos teóricos dos quadrinhos, em que pese o fato de que esse historiador apresenta uma explicação que articula as dimensões políticas, estéticas e cognitivas da cultura histórica. Segundo Saliba (1999, p. 437), imagens canônicas são ícones coercivos, pois são "imagens-padrão ligadas a conceitos chaves de nossa vida 
social e intelectual". São, além disso, pontos de referência de caráter inconsciente, baseados em significados subliminares relacionados às estruturas de poder e que permitem uma identificação coletiva. Saliba fornece, como exemplo, os manuais didáticos de História repletos de imagens canônicas, tais como o quadro de Pedro Américo sobre a Independência do Brasil.

O poder desses ícones canônicos está na disposição típica de narrativas tradicionais e exemplares: os sujeitos, os professores e os estudantes acostumaram-se com elas, ao ponto de não conseguirem imaginar outra possibilidade de representar, significar ou valorar determinado caso no passado, pois não existe a possibilidade de estranhamento próprio às imagens alternativas. Quando estudantes e professores entram em contato com imagens alternativas desestruturam esses estereótipos e ocorre a rejeição em nome de uma verdade dogmática, reproduzida ao infinito pelas imagens canônicas. Essa atitude leva a outra, mais problemática, que diz respeito à diminuição da capacidade de comparar, e, portanto, de pensar de um modo plural; fechando, assim, o caminho para a intersubjetividade. (SALIBA, 1999, p. 438).

Por conta dissso, narrativas tradicionais "encapsuladas" ficaram evidentes nas histórias em quadrinhos que os jovens pesquisados desenharam. (FRONZA, 2012).

FIGURA 9 - HISTÓRIAS EM QUADRINHOS PRODUZIDAS POR JOVENS ESTUDANTES: BEATRIZ

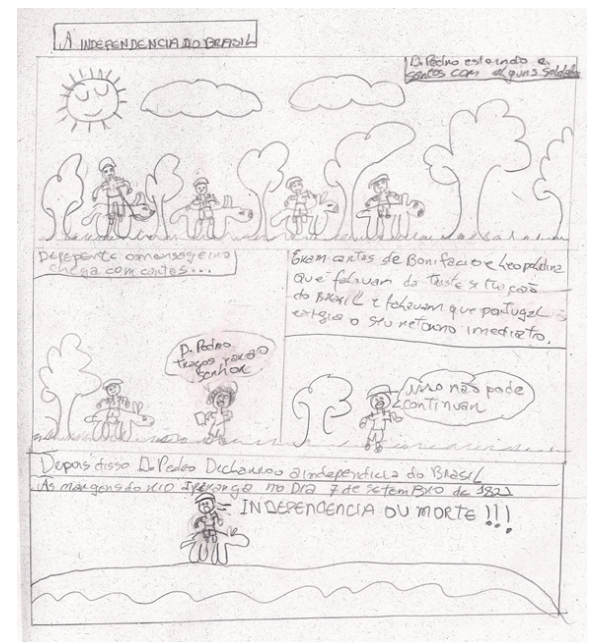

FONTE: Beatriz - 16 anos - São João dos Patos (FRONZA, 2012, p. 393). 
Beatriz representou uma história em quadrinhos que expressa uma consciência histórica tradicional. A imagem canônica de D. Pedro sobre o cavalo, gritando "Independência ou morte!" marca, como na maioria dos quadrinhos representados pelos jovens investigados, uma adesão à interpretação tradicional dessa situação do passado. A participação do mensageiro é destacada por uma tarja no quadrinho em que este personagem aparece. Outro vestígio da adesão de Beatriz à estrutura narrativa esquemática, vinculada à tradição, está na tarja do último quadro que representa D. Pedro declarando a Independência: a indicação do rio Ipiranga e da data 7 de setembro de 1822.

O problema, apontado por Saliba (1999, p. 440-441, 449), é a falta de reflexão sobre os ícones. Isto porque as imagens canônicas criam a impressão de realidade, exatamente porque sua disposição do tempo é a dimensão do presente. As imagens esmagam os jovens no seu próprio presente sequestrando a capacidade de pensar historicamente. O poder do uso público da História, nesses ícones, não está exatamente na representação da imagem sobre o presente, mas sim no uso da imagem de uma experiência ou personagem do passado, que, quando canonizada, fica universalizada em todos os lugares onde o caso no passado é abordado: nas aulas de História, nos livros didáticos, nos filmes, minisséries e até nos quadrinhos. O que deveria ser a diferença temporal entre presente, passado e futuro passa a ser uma imersão irrefletida e alienada no cotidiano.

Em proximidade com as ideias de Lukács $(2003,2010)$, criticar as imagens é tentar "quebrar com o efeito de real que elas provocam". (SALIBA, 1999, p. 440). É necessário sintetizar a análise das imagens contra a superabundância na mídia e na sociedade. Não é fornecendo uma confusão de imagens desconexas ou ilustrativas que fará os estudantes tornarem sua consciência histórica mais complexa, mas com a investigação detalhada de poucas e significativas imagens por meio da comparação. O uso de imagens alternativas, que causem o sentimento estético do humor, pode ser vital porque possibilitam a consciência do distanciamento entre o passado e o presente, abrindo espaço, assim, para um primeiro passo de um processo de ordenamento do tempo.

Um exemplo disso está presente na narrativa histórica gráfica de Marjane. 
FIGURA 10 - HISTÓRIAS EM QUADRINHOS PRODUZIDAS POR JOVENS ESTUDANTES: MARJANE

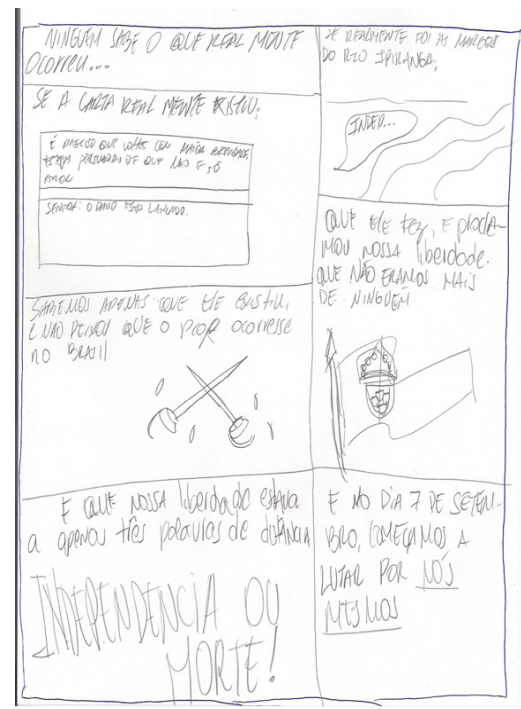

FONTE: Marjane - 16 anos - Curitiba (FRONZA, 2012, p. 415).

Marjane compôs uma história em quadrinhos que apresenta um diálogo entre a narrativa tradicional sobre a Independência do Brasil e uma nova narrativa aberta para o futuro. A narrativa da jovem põe em dúvida a precisão dos marcos espaciais e dos acontecimentos que levaram à Independência. $\mathrm{O}$ caráter evanescente das imagens alternativas é flagrante, pois em um balão do segundo quadrinho a palavra Independência aparece só parcialmente como que desaparecendo da imagem. $\mathrm{O}$ valor que mobiliza esses quadros, à primeira vista tradicionais, é a liberdade, que no início está vinculada às ações e intenções de D. Pedro. Mas no último quadrinho, mesmo com a referência temporal da data de 7 de setembro, a liberdade sai da referência a este personagem histórico e passa a ser compartilhada por todos os brasileiros com a frase "começamos a lutar por nós mesmos".

É perceptível que, para evitar o poder dos ícones canônicos, a jovem não representou o personagem D. Pedro, mas somente a sua fala, como se fosse uma senha para uma mudança histórica estrutural que sequer tinha imaginado: o processo histórico que culminou, no futuro do passado, com a liberdade de todo o povo brasileiro que a toma em suas mãos. Possivelmente, esse é o significado da invisibilidade desse personagem nos quadrinhos. 
Segundo Rüsen (2001, p. 173), quando uma determinada experiência do passado não permite a apreensão do significado histórico da constituição narrativa de sentido é necessário lançar mão de uma "dialética negativa da constituição de sentido", para que a dimensão da historicidade humana seja explicitada ao narrar. Essa jovem mobilizou a dimensão estética da cultura histórica, relacionada aos quadrinhos, para libertar o sentido cognitivo e ético do significado de uma experiência do passado, por meio de uma negação dialética. As narrativas tradicionais, juntamente com as imagens canônicas sobre a Independência, recalcaram há tempos o significado histórico não realizado nessa experiência do passado, e ainda por se cumprir no presente, que dá sentido às expectativas de futuro: o de que todos os homens e mulheres são dignos de reconhecerem e serem reconhecidos como livres e iguais.

No entanto, foram raros os estudantes que conseguiram superar o poder alienante das imagens canônicas. Outra alternativa possível para a superação do processo de internalização da cultura escolar dominante pode ser a investigação de histórias em quadrinhos diretamente voltadas para a orientação de sentido no tempo.

\section{e) Histórias em quadrinhos biográficas, autobiográficas ou investigativas}

A quinta possibilidade investigativa das histórias em quadrinhos voltadas para a aprendizagem histórica ainda é pouco pesquisada no ensino de História e ainda precisa ser mais bem investigada no campo de pesquisa da Educação Histórica, ainda que no campo da historiografia da linguagem dos quadrinhos já existam alguns trabalhos. Seu perfil se caracteriza por investigar narrativas históricas gráficas de caráter biográficos, autobiográficos e/ou até mesmo investigativos sobre sujeitos e eventos históricos significativos para a história da humanidade: a Guerra Civil Americana, a Primeira Guerra Mundial, o holocausto nazista, as bombas de Hiroshima, as revoltas populares, a guerra de libertação da Palestina, a formação do movimento estudantil de um país, a constituição do modo de viver ocidental, etc. (WITEK, 1989; GUNDERMANN, 2007). Além disso, discutem as implicações que este tipo de quadrinhos pode trazer para as discussões relativas à Didática da História.

A diferença em potencial deste tipo de investigação é que as histórias em quadrinhos passam a ser perspectivadas, a partir do princípio epistemológico da narrativa histórica, como uma forma de expressão da orientação de sentido no tempo dos sujeitos que expressam o diálogo entre as experiências de sofrimento do passado que constituiem as interpretações e problematizações do presente e estruturam as perspectivas utópicas de futuro. 
Uma obra seminal nesta perspectiva é a de Joseph Witek (1989), que se propôs a investigar histórias em quadrinhos biográficas e autobiográficas como narrativas históricas que buscam superar o escapismo deste tipo de mídia por meio de temas como os conflitos culturais, na história ocidental, as fronteiras entre a culpa e o sofrimento no interior das famílias, e os desafios e triunfos dos sujeitos na práxis contemporânea. Autores como Jack Jackson (Los Tejanos, Comanche Moon), Art Spiegelman (Mauss) e Harvey Pekar (American Splendor) destruíram as antigas fórmulas narrativas das histórias em quadrinhos ao injetarem os valores e os significados históricos do sentido de orientação no tempo nestes artefatos culturais. São quadrinhos que combatem o consenso didático da história tradicional pautada no nacionalismo e no etnocentrismo; e são narrativas históricas gráficas que propõem perspectivas interculturais que recuperam o narrar dos despossuídos e marginalizados pela tradição e pela história curricularizada. (WITEK, 1989, p. 3-4).

Outra obra relevante para esta perspectiva de investigação é a de Christine Gundermann (2007), que propõe analisar as histórias em quadrinhos biográficas e autobiográficas no âmbito da Didática da História alemã. (BERGMANN, 1990; BORRIES, 1994, 1996; PANDEL, 1999; RÜSEN, 2007). Partindo do princípio epistemológico de que os quadrinhos são narrativas históricas, a autora defende que as narrativas gráficas de autores como Art Spiegelman (Mauss), Jacques Tardi (O grito do povo) e Joe Sacco (Palestina) podem contribuir para formas de aprendizagem histórica significativa que desenvolvam a emoção e a imaginação dos jovens e forneçam sentido de orientação temporal para as crianças e jovens.

\section{FIGURA 11 - HISTÓRIAS EM QUADRINHOS (AUTO)BIOGRÁFICAS E INVESTIGATIVAS: NOTAS SOBRE GAZA}

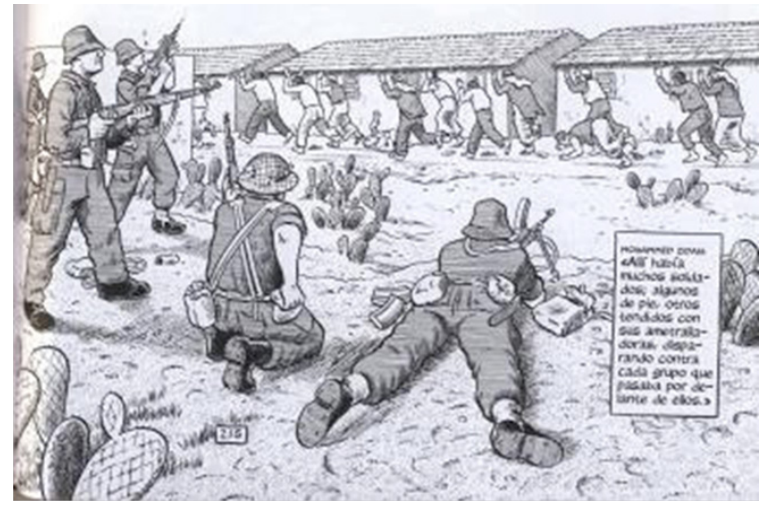

FONTE: SACCO (2010, p. 215). 
Em sua obra, Gundermann (2007, p. 148-161) apresenta formas de investigação das ideias históricas dos jovens estudantes do Ensino Médio por meio da produção de narrativas biográficas e autobiográficas desses sujeitos escolares. Fazendo uso de duas categorias de análise dos quadrinhos produzidos pelos jovens que estudam no Ensino Médio na Alemanha, "Ich-Perspektive" (perspectiva em primeira pessoa) e "Allwissender Erzähltyp" (narrativa-tipo onisciente), a autora investiga o tipo de identidade histórica que os jovens constroem de si e do outro quando produzem narrativas gráficas sobre suas carências de orientação temporal no universo escolar, no mundo do trabalho e na vida social. (GUNDERMANN, 2007, p. 153).

Esses investigadores estão apresentando os primeiros passos para pesquisas de narrativas que tematizam formas de intersubjetividade a partir da orientação de sentido do tempo presentes na relação entre os jovens e os quadrinhos. Compreendo que a produção do autoconhecimento pelos jovens a partir de sua aprendizagem histórica passa pela internalização de algo do narrar em suas vidas. Defendo que esse algo tem a ver com a confiabilidade das narrativas em quadrinhos. Por isso é necessário que sejam criados parâmetros que indiquem o que é ou não é confiável nessas narrativas históricas gráficas quando se refere à formação da identidade histórica desses sujeitos. Desse modo, busco entender se a intersubjetividade está relacionada com a maneira como os jovens tomam para si o conhecimento, se tem a ver com o tipo de fonte que eu usei. Uma fonte que estetiza o passado.

\section{Considerações finais: alguns resultados empíricos}

A partir deste estudo, compreendo que as histórias em quadrinhos podem ser fios condutores para a construção da narrativa que os estudantes constroem para si na relação que têm com a escola e a orientação para práxis da vida humana. Com isso, é possível investigar os critérios de orientação temporal relativos às formas de aprendizagem histórica que estes jovens estão construindo quando entram em contato com esses artefatos da cultura histórica.

Esses resultados permitem compreender que as histórias em quadrinhos, enquanto narrativas históricas gráficas, permitem aos jovens revelar as formas de subjetividades construídas na sua relação com a forma escolar. É perceptível que a cultura juvenil fornece critérios estéticos e cognitivos para que sejam avaliados os modos como esses sujeitos apropriam-se das experiências do passado e quais os valores que eles utilizam para selecioná-las e significá-las. 
Ainda está por se construir uma investigação sobre o tipo de orientação temporal que os jovens constroem quando são confrontados com narrativas históricas gráficas biográficas e autobiográficas que forneçam valores e significados históricos que façam sentido para suas vidas práticas e orientem a formação de suas identidades históricas como um processo criativo de autoconhecimento. Portanto, os quadrinhos podem ser fios condutores para a construção da narrativa que os estudantes constroem para si na relação que têm com a escola e a orientação para práxis da vida humana. Permitem que desenvolvam operações mentais da consciência histórica que conduzam para um posicionamento no mundo em prol do princípio da humanidade enquanto igualdade.

\section{REFERÊNCIAS}

ASHBY, R. Desenvolvendo um conceito de evidência histórica: as idéias dos estudantes sobre testar afirmações factuais singulares. Educar em Revista, Curitiba: UFPR, n. especial, p. 151-170, ago. 2006.

BARBOSA, A. V. A. Histórias em quadrinhos sobre a História do Brasil em 1950: a narrativa dos artistas da EBAL e outras editoras. 253 p. Dissertação (Mestrado em Comunicação) - Escola de Comunicações e Arte, Universidade de São Paulo, São Paulo, 2006.

BERGMANN, K. A História na reflexão didática. Revista Brasileira de História, São Paulo, v. 9, n. 19, p. 29-42, set. 1989/fev. 1990.

BONIFÁCIO, S. de F. História e (m) quadrinhos: análises sobre a História ensinada na arte seqüencial. 209 p. Dissertação (Mestrado em Educação) - Programa de Pós-Graduação em Educação, Universidade Federal do Paraná, Curitiba, 2005.

BORRIES, B. von. Von gesinnungsbildenden Erlebnissen zur Kultivierung der Affekte? Über Ziele und Wirkungen von Geschichtslernen in Deutscheland. In: MÜTTER, B.; UFFELMANN, U. (Ed.). Emotionen und historisches Lernen. Forschung - Vermittlung - Rezeption. Frankfurt/M., 1994. 2 v. p. 67-92.

BORRIES, B. von. Imaginierte Geschichte. Die biographische Bedeutung historischer Fiktionen und Phantasien. Köln, 1996.

CABRINI, C.; CATELLI JUNIOR, R.; MONTELLATO, A. História temática: tempos e culturas. São Paulo: Scipione, 2004.

CARRIER, D. The Aesthetics of comics. University Park: The Pennsylvania State University Press, 2000.

CASTRO, J. de A. e; ZALLA, R. História Geral: História para a escola moderna. São Paulo: IBEP, 1971. 
DANTO, A. C. Narration and knowledge. New York: Columbia University Press, 2007. DUBET, F.; MARTUCCELLI, D. En la escuela: Sociología de la experiência escolar. Buenos Aires: Editorial Losada, 1998.

DINIZ, A.; EDER, A. A Independência do Brasil. São Paulo: Escala Editorial, 2008.

EISNER, W. Quadrinhos e arte seqüencial. São Paulo: Martins Fontes, 1999.

EISNER, W. Narrativas gráficas. São Paulo: Devir, 2005.

FRONZA, M. O significado das histórias em quadrinhos na Educação Histórica dos jovens que estudam no Ensino Médio. 170 p. Dissertação (Mestrado em Educação) - Programa de Pós-Graduação em Educação, Universidade Federal do Paraná, Curitiba, 2007.

FRONZA, M. A intersubjetividade e a verdade na aprendizagem histórica de jovens estudantes a partir das histórias em quadrinhos. 465 p. Tese (Doutorado em Educação) - Programa de Pós-Graduação em Educação, Universidade Federal do Paraná, Curitiba, 2012.

GAGO, M. Pluralidade de olhares: construtivismo e multiperspectiva no processo de aprendizagem. Lisboa: Pensar a educação, 2012.

GONÇALO JUNIOR. A guerra dos gibis: a formação do mercado editorial brasileiro e a censura aos quadrinhos, 1933-64. São Paulo: Companhia das Letras, 2004.

GOSCINNY, R.; UDERZO, A. Asterix e Cleópatra. Tradução de: RODRIGUES, Paulo Madeira. Rio de Janeiro: Record, 1985.

GUNDERMANN, C. Jenseits von Asterix: Comics im Geschichtsunterricht. Schwalbach: Wochenschau Verlag, 2007.

HOBSBAWM, E. J. Era dos extremos: o breve século XX. São Paulo: Companhia das Letras, 1995.

LEE, P. Understanding History. In: SEIXAS, P. (Ed.). Theorizing historical consciousness. Toronto/Buffalo/London: University of Toronto Press, 2006. p. 129-164.

LEE, P.; ASHBY, R. Progression in historical understanding among students ages 7-14. In: STEARNS, P. N.; SEIXAS, P; WINEBURG, S. (Ed.). Knowing, teaching and learning History: national and international perspectives. New York: New York University Press, 2000. p. 199-222.

LUKÁCS, G. História e consciência de classe: estudos sobre a dialética marxista. São Paulo: Martins Fontes, 2003.

LUKÁCS, G. Marxismo e teoria da literatura. 2. ed. São Paulo: Expressão Popular, 2010.

McCLOUD, S. Desvendando os quadrinhos. São Paulo: Makron Books, 2005.

McCLOUD, S. Reinventando os quadrinhos. São Paulo: Makron Books, 2006. 
NERES, J. M. A produção didática de História em Quadrinhos: Julierme e a história para a escola moderna (1969-1975). Dissertação (Mestrado em Educação) - Programa de Pós-Graduação em Educação, Faculdade de Educação, Universidade de São Paulo, São Paulo, 2005.

OAKESHOTT, M. Sobre a História e outros ensaios. Rio de Janeiro: Topbooks Editora, 2003.

PAIVA, M.; SCHWARCZ, L. M. Da Colônia ao Império: um Brasil para inglês ver e latifundiário nenhum botar defeito. 10. ed. São Paulo: Brasiliense, 1995.

PANDEL, H.-J. Comics. Gezeichnete Narrativität und gedeutete Geschichte. In: PANDEL, H.-J.; SCHNEIDER, G. (Org.). Handbuch Medien im Geschichtsunterricht. Schwalbach: Wochenschau Verlag, 1999. p. 339-364.

RÜSEN, J. A razão histórica: Teoria da História: os fundamentos da ciência histórica. Brasília: UnB, 2001.

RÜSEN, J. História viva: Teoria da História III: formas e funções do conhecimento histórico. Brasília: UnB, 2007.

RÜSEN, J. ¿Qué es la cultura histórica?: Reflexiones sobre una nueva manera de abordar la historia. [Unpublished Spanish version of the German original text in K. Füssmann, H. T. Grütter and J. Rüsen, eds. (1994). Historische Faszination. Geschichtskultur heute. Keulen, Weimar and Wenen: Böhlau, p. 3-26], 2009. Disponível em: <http://www. culturahistorica.es/ruesen/cultura_historica.pdf>. Acesso em: 27 maio 2011.

RÜSEN, J. Aprendizagem histórica: esboço de uma teoria. In: RÜSEN, J. Aprendizagem histórica: fundamentos e paradigmas. Curitiba: W.A Editores, 2012. p. 69-112.

SACCO, J. Notas sobre Gaza. Tradução de: BOIDE, Alexandre. São Paulo: Companhia das Letras, 2010.

SALIBA, E. T. As imagens canônicas e o Ensino de História. In: SCHMIDT, M. A.; CAINELLI, M. R. III Encontro Perspectivas do Ensino de História. Curitiba: Aos Quatro Ventos, 1999. p. 434-452.

SCHMIDT, D. Historiar: fazendo, contando e narrando a História. São Paulo: Scipione, 2002. (Coleção Historiar $-6^{\mathrm{a}}$ série).

SCHMIDT, M. A. Cognição histórica situada: que aprendizagem histórica é essa? In: SCHMIDT, M. A.; BARCA, I. Aprender História: perspectivas da Educação Histórica. Ijuí: Unijuí, 2009. p. 21-51.

SEIXAS, P. Students' understanding of historical significance. Theory and Research in social Education, v. 22, n. 3, p. 281-304, 1994.

SNYDERS, G. Alegria na escola. São Paulo: Manole, 1988.

SOBANSKI, A. de Q. et al. Ensinar e aprender História: histórias em quadrinhos e canções. Curitiba: Editora Base, 2010. 
SOUZA, M. Você sabia? Abolição dos escravos. Rio de Janeiro: Globo, cerca 2005.

WILLIAMS, R. La larga revolución. Buenos Aires: Nueva Visión, 2003.

WITEK, J. Comic books as History: the narrative art of Jack Jackson, Art Spiegelman and Harvey Pekar. Jackson: University Press of Mississipi, 1989.

Texto recebido em 24 de março de 2016. Texto aprovado em 27 de março de 2016. 